\title{
ENHANCING PERFORMANCE CHARACTERISTICS OF EQUIPMENT OF SEA AND RIVER TRANSPORT BY USING EPOXY COMPOSITES
}

\author{
Andriy Buketov ${ }^{1}$, Pavlo Maruschak ${ }^{2}$, Oleksandr Sapronov ${ }^{3}$, Dmytro Zinchenko ${ }^{4}$, \\ Vitaliy Yatsyuk ${ }^{5}$, Sergey Panin ${ }^{6}$ \\ 1,3,4 Dept of Ship Propulsion Plants Operation and General Engineering Training, \\ Kherson State Maritime Academy, Ukraine \\ ${ }^{2}$ Dept of Industrial Automation, Ternopil Ivan Pul'uj National Technical University, Ukraine \\ ${ }^{5}$ Dept of Chemistry and Biology, Ternopil Volodymyr Hnatyuk National Pedagogical University, Ukraine \\ ${ }^{6}$ Institute of Strength Physics and Materials Science of the Siberian Branch \\ of the Russian Academy of Sciences, Tomsk, Russia
}

Submitted 15 November 2015; resubmitted 7 March 2016; accepted 29 March 2016

\begin{abstract}
Coatings based on epoxy diane oligomer ED-20 are being developed as environmentally benign, foulingresistant marine coatings. Silver oxide and carbonate (mixture) was used as filler, the dispersion of which is $0.5 \mu \mathrm{m}$. It is proved that for the formation of composites with the improved physical and mechanical properties it is necessary to add Mechanical Mixture of Silver Carbonate and Oxide (MMSCO) in the amount of $q=0.050 \ldots 0.250$ pts. wt. into the epoxy diane oligomer ED-20 (100 pts. wt.). The obtained values of impact toughness of composites during the introduction of MMSCO into the binder increased by 2.5 times compared to the epoxy matrix. Moreover, the maximum capacity to resist impact loads, including fracture toughness, was demonstrated by the Composite Material (CM) with the filler content $q=0.050$ pts. wt. Impact toughness of this CM is $a=18.53 \mathrm{~kJ} / \mathrm{m}^{2}$. The developed materials and protective coatings based on them were used on the dry cargo ship Oles Honchar.
\end{abstract}

Keywords: ship; corrosion; epoxy composites; fracture; coatings.

\section{Introduction}

The development of sea and river transport calls for improving production while reducing the cost of production, operation, rehabilitation, maintenance and repair of power equipment (Heller 1970; Zayed et al. 2013; Atta et al. 2008). To-date, special attention is paid to the restoration and protection of stern tube systems from corrosive environments and wear. However, considerable damage is caused by corrosion, which primarily affects deck mechanisms. Therefore, the operation of mechanisms or structural elements under low temperature and high humidity conditions necessitates the creation of new materials with high performance characteristics. It should be noted that of all the known thermosetting polymers used as binders for Composite Materials (CMs), epoxy oligomers, which meet a set of requirements for the polymer matrix of high-strength composites, are used most often (Stukhlyak et al. 2015; Buketov, Krasnen'kyi 2013; Dobrotvor et al. 2009; Atta et al. 2008). A wide range of properties of epoxy composites allows them to be used as ready-made products or protective covers. Moreover, epoxy composites filled with binders of various form, nature and dispersion characteristics ensure such properties as durability, chemical resistance to the marine environment, resistance to variable temperatures, low thermal conductivity, corrosion resistance compared to metal, when they are used in power equipment of maritime transport (Buketov et al. 2015a, 2015b, 2016; Decò et al. 2012). However, despite a considerable amount of information about the research on the properties of epoxy composites, increasingly more attention has been paid to the practical application of such materials and study of their behavior in operation. Accordingly, the developed materials and protective coatings based on them are planned to be used on the dry cargo ship Oles Honchar with the deadweight of 6315 tons, which is operated under the influence of the aggressive river and sea environment.

In-service damage of the equipment of stern tube systems, including bearings, is commonly represented

Corresponding author: Pavlo Maruschak

E-mail: maruschak.tu.edu@gmail.com 
by the abrasive and adhesive wear and delamination, which leads to a premature failure of a structural element (Caines et al. 2015; James, Hattingh 2015). The main materials used in the production of bearings for stern tube systems are bakaut, tufnol, textolite, kaprolone, babbit, and others. Given the main types of destruction and a wide range of properties, most promising in this regard is the application of epoxy composites that can be used as materials for the production of stern tube bearings, as well as protective coatings. This can significantly improve physical, mechanical, thermal, corrosion and other performance characteristics of stern tube systems and mechanisms that are operated under the influence of static and dynamic loads (Montemor 2014; Dong et al. 2012).

The purpose of this work is to develop epoxy composites with enhanced performance characteristics in order to extend the service life of the equipment of sea and river transport.

\section{Justification of the Choice of Filler for Epoxy Composite}

The hull of sea ships, their systems, devices, units and mechanisms are operated in conditions of high humidity, exposure to salt spray or salt water. The effective protection of the ship metal from corrosion damage is achieved in various ways, including by means of applying protective lubricants, epoxy composite coatings, inhibitors and other anti-corrosion agents (Melchers 2012; Gudze, Melchers 2008; Melchers, Jeffrey 2008). There are cases of delamination of the swollen upper layers of paints based on the amide resin, which occur in ships, mainly under the influence of seawater in the form of precipitation (Nakai et al. 2007). Therefore, the choice of hybrid materials based on carbonate and silver oxide (MSKOS) for the sea transport is explained by the fact that they have a set of specific properties (Pascault, Williams 2010; Buketov et al. 2015a, 2015b, 2016):

- mechanical properties include an increased cohesion, low coefficient of friction, self-lubrication and wear resistance, as well as high strength of coatings, lack of dishing or flaking;

- chemical properties include resistance to a prolonged exposure to corrosive environments, salt fog and humidity, in particular, seawater. The filler acts as inhibitor of corrosion processes in case of immersion in the acidic environment, providing an anode and cathodic protection. There are also bactericidal properties and resistance to biocorrosion;

- technological properties: the filler is a catalyst in the crosslinking of epoxy matrix, and is determined by its activity in the interfacial interactions in the formation of composites. The protective properties of such composites are associated with the chemical bond between the matrix and the filler surface, as was proved in this paper;

- environmental properties allow avoiding the use of toxic anti-corrosion fillers;
- technical properties allow increasing durability of coatings, reducing the number of deposited layers, increasing turnaround time.

At the initial stage, we synthesized silver carbonate with dispersion of $0.5 \mu \mathrm{m}$, whose characteristics are described in detail in (Buketov et al. 2015a, 2015b, 2016).

This filler has a high specific surface area, significant activity upon interaction with the epoxy binder, which can significantly improve the physical and mechanical properties of epoxy composites developed. However, the technology of synthesis of such disperse particles envisages their drying in a dark box (without sunlight). A Mixture of Carbonate and Silver Oxide (MSKOS) is easier to use, because the technology of its synthesis involves drying the particles under the influence of sunlight in the air. A filler of this kind contains silver carbonate, which is the catalyst in crosslinking of the epoxy matrix and silver oxide, which is also marked with the activity in interfacial interactions in the formation of composites (Yu et al. 2013; Atta et al. 2014).

Today, the introduction of the known fillers, such as silicon carbide, titanium carbide, boron carbide, aluminum oxide, titanium oxide, brown sludge etc., also enhances the performance of epoxy composites. However, the chosen filler (MSKOS) is more active in the interfacial interaction, which occurs in crosslinking epoxy composites, providing a greater volume of surface layers around the filler particles in the matrix (Buketov et al. 2015a, 2015b, 2016). This, in turn, will allow increasing the durability of the polymer, which involves improving the cohesive strength of composites.

Another important aspect in the choice of the filler is not only its content in the composite, but the size of particles. Today, it is appropriate to use nanopowder particles. However, it is known that the introduction of microdisperse particles in the binder also provides an improved performance of composites (Buketov et al. 2015a, 2015b, 2016). Therefore, in this paper we used the filler with the size of $0.5 \mu \mathrm{m}$, which is between the nano- and microrange. In our view, introducing a low-content filler MSKOS $(0.5 \mu \mathrm{m})$ in the epoxy binder will allow using the advantages of nano- and microdisperse particles at a time.

\section{Materials and Research Technique}

Based on the above, epoxy diane oligomer ED-20 (GOST 10587-84) was selected as the main binder component in the preparation of the CM. Polietylenpoliamin PEPA (the hardener) (TU 6-05-241-202-78) was used for crosslinking of epoxy compositions, which allows for the material hardening at room temperatures. It is known (Stukhlyak et al. 2015; Buketov, Krasnen'kyi 2013) that PEPA is a low molecular substance, which consists of the following interrelated components: $\left[-\mathrm{CH}_{2}-\mathrm{CH}_{2}-\mathrm{NH}-\right]_{n}$. We administered 10 pts. wt. of the hardener per 100 pts. wt. of epoxy diane oligomer ED-20.

Silver oxide and carbonate (mixture) was used as the filler, the dispersion of which is $0.5 \mu \mathrm{m}$. Note that the 
filler was obtained as a result of exchange (1) and decomposition (2) reactions:

$$
\begin{aligned}
& 2 \mathrm{AgNO}_{3}+\mathrm{K}_{2} \mathrm{CO}_{3} \rightarrow \mathrm{Ag}_{2} \mathrm{CO}_{3} \downarrow+2 \mathrm{KNO}_{3} ; \\
& \mathrm{Ag}_{2} \mathrm{CO}_{3} \rightarrow \mathrm{Ag}_{2} \mathrm{O}+\mathrm{CO}_{2} \uparrow .
\end{aligned}
$$

Characteristics of the epoxy diane oligomer, the filler and the hardener are given in Table. The filler was added to the binder in the amount of $0.025 \div 1.00$ pts. wt. per 100 pts. wt. of epoxy diane oligomer ED-20. The filler synthesis technology is different because the material is dried under sunlight in the air. This enabled us to ensure the stability of the sediment and, accordingly, obtain silver carbonate $(8 \div 10 \%)$ and silver oxide with a high concentration of the active ingredient $(90 \div 92 \%)$. Thus, we obtained the filler in the form of a (MMSCO).

Table. Characteristics of epoxy binding

\begin{tabular}{|l|c|c|c|}
\hline \multicolumn{1}{|c|}{ Characteristics } & $\begin{array}{c}\text { Epoxy diane } \\
\text { oligomer } \\
\text { ED-20 }\end{array}$ & MMSCO & PEPA \\
\hline Molecular weight & 340 & 276 & $215 \div 258$ \\
\hline $\begin{array}{l}\text { Functionality epoxy } \\
\text { groups } f_{\mathrm{EP}}\end{array}$ & 2.0 & - & - \\
\hline $\begin{array}{l}\text { The content of } \\
\text { epoxide groups [\%] }\end{array}$ & $20.0 \div 22.5$ & - & - \\
\hline $\begin{array}{l}\text { The content of } \\
\text { hydroxyl groups [\%] }\end{array}$ & 1.25 & - & - \\
\hline $\begin{array}{l}\text { The content of } \\
\text { nitrogen [\%] }\end{array}$ & - & - & $19.5 \div 22.0$ \\
\hline $\begin{array}{l}\text { The content of } \\
\text { carbon [\%] }\end{array}$ & - & 4.35 & - \\
\hline $\begin{array}{l}\text { The content of } \\
\text { oxygen [\%] }\end{array}$ & - & 4.15 & - \\
\hline $\begin{array}{l}\text { The content of } \\
\text { argentum [\%] }\end{array}$ & $13-20$ & - & 0.9 \\
\hline Viscosity $\eta[\mathrm{Pa} \cdot \mathrm{s}$ ] & 1.160 & 6.077 & 1.050 \\
\hline Density $\rho\left[\mathrm{gr} / \mathrm{cm}^{3}\right.$ ] & & & - \\
\hline
\end{tabular}

The epoxy CM was formed by the following technology: predosing of epoxy diane resin ED-20, heating it to a temperature $T=353 \pm 2 \mathrm{~K}$ and holding at a given temperature over time $\tau=20 \pm 0.1 \mathrm{~min}$; dosing the filler and its further addition to the epoxy oligomer; hydrodynamic combination of epoxy diane oligomer ED-20 and the filler over time $\tau=1 \pm 0.1 \mathrm{~min}$; UltraSound Treatment (UST) of the composition over time $\tau=1.5 \pm 0.1 \mathrm{~min}$; cooling the composition down to room temperature over time $\tau=60 \pm 5 \mathrm{~min}$; addition of the PEPA hardener and mixing the composition over time $\tau=5 \pm 0.1 \mathrm{~min}$. Thereafter, the CM was hardened in the experimentally established mode: the formation of specimens and their holding over time $\tau=12.0 \pm 0.1 \mathrm{~h}$ at $T=293 \pm 2 \mathrm{~K}$, heating with velocity $\mathrm{U}=3 \mathrm{~K} / \mathrm{min}$ to a temperature $T=393 \pm 2 \mathrm{~K}$, holding CM over time $\tau=2.0 \pm 0.05$ hours, its slow cooling to a temperature $T=293 \pm 2 \mathrm{~K}$. In order to stabilize structural processes in the $\mathrm{CM}$, specimens were held over time $\tau=24 \mathrm{~h}$ in the air at a temperature $T=293 \pm 2 \mathrm{~K}$, followed by experimental tests.
The adhesive strength between the matrix and the metal base was investigated by measuring fracture stress ('method of fungi') in case of uniform separation of the couple of bonded specimens according to the GOST 14760-69. Research of the adhesive strength in shear was carried out according to the GOST 14759-69 by measuring the tearing strength of adhesive joints of steel specimens on the automated tearing machine UM-5 at the loading rate $v=10 \mathrm{~m} / \mathrm{s}$. The diameter of the working part of steel specimens was $d=25 \mathrm{~mm}$ in isolation. It should be noted that the adhesion area of the specimens tested in isolation and shear was identical.

Residual stresses in the matrix were determined by the console method (Stukhlyak et al. 2015; Buketov, Krasnen'kyi 2013). Coatings with thickness $\delta=0.3 \div 0.8 \mathrm{~mm}$ were formed on a steel base. The base parameters were: total length $l=100 \mathrm{~mm}$; working length $l_{0}=80 \mathrm{~mm}$; thickness $\delta=0.3 \mathrm{~mm}$.

Fracture stress and modulus of elasticity in bending of the CM were determined according to the GOST 464871 and GOST 9550-81, respectively. Specimen parameters were: length $l=120 \pm 2 \mathrm{~mm}$, width $b=15 \pm 0.5 \mathrm{~mm}$, height $h=10 \pm 0.5 \mathrm{~mm}$.

Impact toughness was determined by the Charpy method in accordance with the GOST 4647-80 on the pendulum impact testing machine MK-30 at $T=298 \pm 2 \mathrm{~K}$ and relative humidity $d=50 \pm 5 \%$. We used samples with the size $(63.5 \times 12.7 \times 12.7) \pm 0.5 \mathrm{~mm}$.

The deviation of values during the studies of the physical and mechanical properties of CM was $4 \div 6 \%$ from the nominal value.

IR spectra were recorded on the spectrophotometer IRAffinity-1 (Japan) within the region of wave numbers $v=750 \div 1500 \mathrm{~cm}^{-1}$ by a single-beam method in the reflected light. Wavelength scanning by wave numbers $\lambda^{-1}=v$ was performed on the $225 \mathrm{~mm}$ diagram in the range of selected frequencies. Wave numbers, intensity of transmission, half-width and the area of absorption bands were determined using the IRSolution software. The accuracy in determining the wave number was $v= \pm 0.01 \mathrm{~cm}^{-1}$, and in determining the peak location it was $v= \pm 0.125 \mathrm{~cm}^{-1}$. The photometric accuracy was $\pm 0.2 \%$ during programmed control of the slit over integration time $t=10 \mathrm{~s}$. The step of integration was $\Delta \lambda=4 \mathrm{~cm}^{-1}$. IR spectra were deciphered by the method described in (Stukhlyak et al. 2015; Buketov, Krasnen'kyi 2013).

The investigations into the material structure were performed on the metallographic microscope XJL-17AT equipped with camera Levenhuk C310 NG (3.2 mega pixels). Zoom range was changed from $\times 100$ to $\times 1600$. Specimens were examined at a magnification of $\times 200$ and $\times 400$. For the processing of digital images we used Levenhuk ToupView software.

\section{Research Results and Their Discussion}

To determine the optimal filler content in the epoxy matrix with improved properties, the adhesive strength in isolation $\sigma_{a}$, shear $\tau$ and residual stresses $\sigma_{\text {res }}$ were determined at the initial stage of the investigation. 
It is established experimentally (Fig. 1, curve 1) that the adhesive strength of the matrix in the above modes of crosslinking was $\sigma_{a}=24.4 \mathrm{MPa}$. The addition of the filler in the amount of $q=0.025$ pts. wt. to the epoxy oligomer leads to a monotonic increase in the adhesive strength to $\sigma_{a}=38.0 \mathrm{MPa}$ in isolation. The maximum on the curve showing the dependence of the adhesion joints in isolation was observed during the administration of MMSCO in the amount of $q=0.050$ pts. wt. (Fig. 1, curve 1). The value of the adhesive strength in isolation of the $\mathrm{CM}$ was $\sigma_{a}=40.05 \mathrm{MPa}$. It was believed that the enhancement of the adhesion characteristics with increasing the filler content causes the formation of physical links in the structural grid due to the interaction between the oligomer segments and the active centers on the surface of the filler particles. This increases the velocity of physical and chemical process of polymerization during the formation of the CM structure. As a result, the adhesion properties of such materials are improved. Further addition of the filler in the amount of $q=0.100 \div 0.500$ pts. wt. leads to a slight decrease in the adhesive properties in isolation. Moreover, the material is characterized by the adhesive strength within the range of $\sigma_{a}=$ $36.10 \div 37.35 \mathrm{MPa}$. It should be noted that filling the $\mathrm{CM}$ with MMSCO particles in the amount over $q=0.500$ pts. wt. causes a decrease in the adhesive strength, and the value of the CM adhesion $\left(\sigma_{a}=26.95 \mathrm{MPa}\right)$ becomes approximated to the adhesion of the epoxy matrix $\left(\sigma_{a}=\right.$ 24.4 MPa). This allows stating the inappropriateness of using the CM with such a content of MMSCO. It was believed that a decrease in the adhesive strength in case of the above filler content is caused by the oversaturation of the reactive groups, which, in turn, leads to an incomplete crosslinking of macromolecules of the system components. At the same time, it should be noted that the obtained research results make it possible to conclude that, in order to obtain materials of various functional purpose, it is possible to use CMs with the MMSCO content within the range of $q=0.100 \div 0.500$ pts. wt., since the adhesive strength is reduced insignificantly (within $\Delta \sigma_{a}=1.25 \mathrm{MPa}$ ).

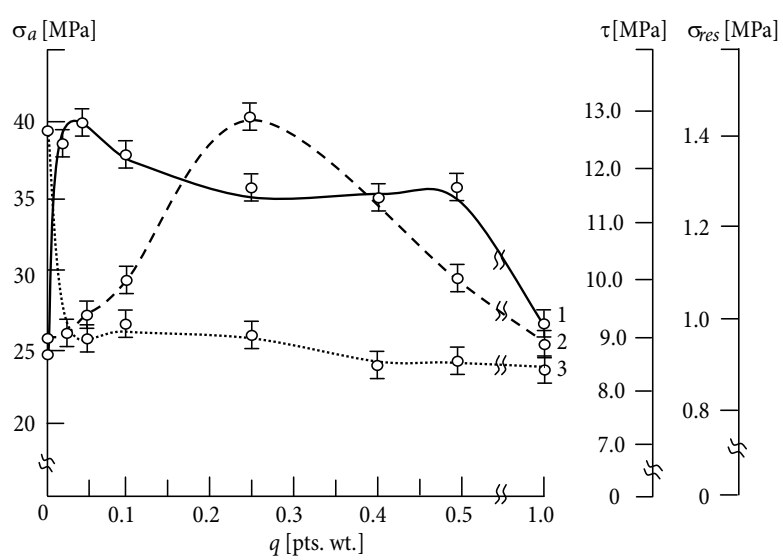

Fig. 1. Dependence of adhesive strength and residual stresses of the epoxy matrix on the filler content MMSCO: curve 1 - adhesive strength in isolation $\sigma_{a}$; curve 2 - adhesive strength in shear $\tau$; curve 3 - residual stresses $\sigma_{\text {res }}$
Additionally, the studies of the adhesion strength in shear were conducted (Fig. 1, curve 2). It is established that the addition of the filler in the amount of $q=0.025 \div 0.100$ pts. wt. leads to a monotonic increase in the adhesive strength in shear. The value of the adhesive strength is $\tau=9.03 \div 9.89 \mathrm{MPa}$. The occurrence of a maximum on the curve showing the dependence of the adhesion strength in shear $(\tau=12.83 \mathrm{MPa})$ on the filler content was found after adding the latter in the amount of $q=0.250$ pts. wt. It was believed that an increase in the adhesive strength was due to an increase in the velocity of physical and chemical processes of polymerization due to the activation of functional groups of the binder ingredients. Subsequent addition of a higher filler content leads to a decrease in the adhesive strength of the $\mathrm{CM}$ in shear.

As a result, of experimental studies it was found that the maximum on the curve showing the adhesion strength in shear does not match the location of the maximum on the curve showing the dependence of the adhesive strength in isolation on the filler content (Fig. 1, curves 1 and 2). This indicates a different magnitude and mechanism of action of normal and tangential stresses on the adhesive strength of the epoxy composite (Stukhlyak et al. 2015; Mouritz et al. 2001). Normal stresses are maximal in isolation; moreover, a significant number of links are broken. However, the angles between atoms and macromolecules of the epoxy binder become elongated in shear, which contributes to the occurrence of transverse forces during the movement of one body along the surface of another body, resulting in shear and normal stresses. Thus, the adhesive strength with different absolute values in isolation and shear are associated with the action of various forces during fracture of materials.

Special attention was paid to residual stresses, which are directly affected by the nature of the filler.

It is established that the residual stress in the matrix treated with ultrasound was $\sigma_{\text {res }}=1.4 \mathrm{MPa}$ (Fig. 1, curve 3 ). When adding MMSCO in the amount of $q=$ $0.025 \div 0.100$ pts. wt., a decrease in residual stresses in the $\mathrm{CM}$ to $\sigma_{\text {res }}=0.95 \div 0.98 \mathrm{MPa}$ was observed. Subsequent increase in the filler content from $q=0.100$ pts. wt. to $q=$ 1.000 pts. wt. contributes to a slight decrease in residual stresses (relative to the CM with the filler content of $q=$ $0.025 \div 0.100$ pts. wt.), indicating a complex mechanism of relaxation processes after the $\mathrm{CM}$ polymerization. The values of residual stresses were $\sigma_{\text {res }}=0.90 \div 0.98 \mathrm{MPa}$. Minor residual stresses in the CM at the maximum adhesive strength $\left(\sigma_{a}=40.05 \mathrm{MPa}\right.$ (with the filler content $q=0.050$ pts. wt.) and $\tau=12.83 \mathrm{MPa}$ (with the filler content $q=0.250$ pts. wt.)) indicate the durability of the protective coatings in operation, as well as their enhanced resistance to delamination.

Therefore, based on the experimental research and given the economic efficiency of using the developed materials, we can say the following. It is advisable to use CMs with the minimal MMSCO content of $q=0.050$ pts. wt. In addition, the maximum adhesive strength of materials is: in isolation $\sigma_{a}=40.05 \mathrm{MPa}$, in shear $\tau=9.45 \mathrm{MPa}$, and residual stresses are $\sigma_{\text {res }}=$ 
$0.95 \mathrm{MPa}$. At the same time, when it is necessary to use CMs or protective coatings to be operated in conditions of normal and tangential forces, it is advisable to use the CM with the MMSCO content of $q=0.150$ pts. wt. The maximum adhesive strength in this case is: in isolation $\sigma_{a}=36.60 \mathrm{MPa}$, in shear $\tau=11.80 \mathrm{MPa}$, and residual stresses $\sigma_{\text {res }}=0.96 \mathrm{MPa}$.

At the next stage, we investigated the physical and mechanical properties of the CM filled with MMSCO.

As stated previously, the above exchange reaction resulted in the formation of argentum carbonate $\left(\mathrm{Ag}_{2} \mathrm{CO}_{3}\right)$ in the form of a sediment and potassium nitrate $\left(\mathrm{KNO}_{3}\right)$, which are present in the binder. As a result of the decomposition reaction, silver oxide $\left(\mathrm{Ag}_{2} \mathrm{O}\right)$ and carbon dioxide $\left(\mathrm{CO}_{2} \uparrow\right)$ were formed. Therefore, with a view to studying the structure of the polymer matrix followed by confirmation of the above assumption, the IRspectral analysis of MMSCO was performed in the range of wave numbers $v=1650 \div 750 \mathrm{~cm}^{-1}$ (Fig. 2).

The IR spectrum analysis of the filler allowed revealing the absorption bands with the frequency $v=$ $786.96 \div 810.10 \mathrm{~cm}^{-1}$ (the relative value of the peak area is $S=47.68 \%$ ), which is typical of ion nitrate (in our case $\mathrm{KNO}_{3}$ ). Absorption bands in the frequency range $v=1199.72 \div 1072.42 \mathrm{~cm}^{-1}$ indicate valence vibrations of $\mathrm{C}-\mathrm{O}$ bonds, and the relative value of the peak area $S=28.39 \%\left(\right.$ at $\left.v=1072.42 \mathrm{~cm}^{-1}\right)$ indicates their significant amount. An absorption band in the frequency range $v=1377.17 \mathrm{~cm}^{-1}$ indicates the presence of acidic residue $\left(\mathrm{CO}_{3}\right)^{2-}$, and the relative value of the peak area $S=$ $40.19 \%$ also indicates their significant amount. An absorption band at a frequency $v=1496.76 \mathrm{~cm}^{-1}$ indicates the presence of nitro-bond $\mathrm{R}-\mathrm{NO}_{2}$ (the relative value of the peak area is $S=59.67 \%$ ).

It was further established that fracture stresses in bending for the epoxy matrix are $\sigma_{b}=48.00 \mathrm{MPa}$ (Fig. 3, curve 1). The addition of the filler in the amount of $q=$ $0.025 \div 0.250$ pts. wt. did not significantly affect fracture stresses, since their value is $\sigma_{b}=48.0 \div 48.10 \mathrm{MPa}$.

It was believed that lower values of properties under the above filler content indicate the presence of impurities in the $\mathrm{CM}\left(\mathrm{KNO}_{3}\right)$. As a result, the content of sol-fraction in the CM increases. Further addition of the filler in the amount of $q=0.400 \div 0.500$ pts. wt. leads to a monotonic increase in fracture stresses in bending from $\sigma_{b}=60.42 \mathrm{MPa}(q=0.400$ pts. wt. $)$ to $\sigma_{b}=70.00 \mathrm{MPa}$ $(q=0.500$ pts. wt.). An increased filler content leads to an increase in the amount of the active centers capable of interacting with the epoxy binder, and the amount of $\mathrm{C}-\mathrm{O}$ bonds (Fig. 2, $v=1072.42 \mathrm{~cm}^{-1}$ ). This explains an increase in fracture stress in bending of the CM. The maximum value of fracture stress in bending $\left(\sigma_{b}=\right.$ $74.45 \mathrm{MPa}$ ) was observed at the MMSCO content of $q=1.000$ pts. wt. It was believed that the mechanism of increasing fracture stresses in bending is as follows. The critical filler content ( $q=1.000$ pts. wt.) creates the conditions for the formation of a material with a large density of the spatial grid. Macromolecules, which are a part of supramolecular structures, change their shape (elongation, twisting, etc.) under load. Therefore, due

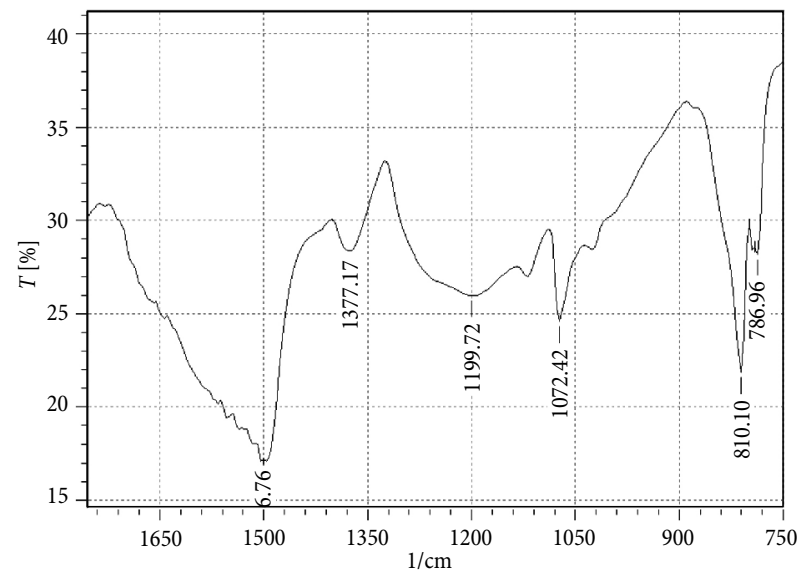

Fig. 2. IR-spectrum of the MMSCO filler in the range of wave numbers $v=1650 \div 750 \mathrm{~cm}^{-1}$

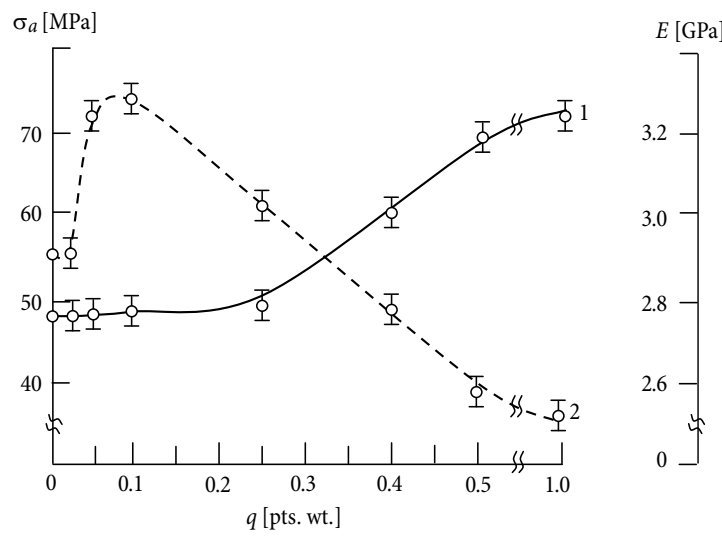

Fig. 3. Dependence of physical and mechanical properties of the matrix on the MMSCO content: curve 1 - fracture stresses in bending $\sigma_{b}$; curve 2 - modulus of elasticity in bending $E$

to the flexibility of the polymer chain, a high elasticity of the CM as a whole is provided. Due to this, the material is characterized by an ability to resist deformation. This assumption is confirmed by the IR-spectral analysis. As shown previously, a significant amount of $\mathrm{C}-\mathrm{O}$ bonds was revealed in the frequency range $v=$ $1273.02 \div 072.42 \mathrm{~cm}^{-1}$.

The dependence of the elasticity modulus in bending on the MMSCO content was investigated in parallel (Fig. 3, curve 2). It is established experimentally that the elasticity modulus of the modified matrix in bending is $E=2.90 \mathrm{GPa}$. When adding MMSCO in the amount of $q=0.025$ pts. wt., an increase in the elasticity modulus was not observed $(E=2.90 \mathrm{GPa})$, moreover, this is consistent with the results of the investigation into fracture stress in bending of the $\mathrm{CM}$ (Fig. 3, curve 1). Introducing the filler in the amount of $q=0.050 \div 0.100$ pts. wt. contributes to a maximum increase in the elasticity modulus to $E=3.24 \div 3.48 \mathrm{GPa}$. Further introduction of the filler in the epoxy binder (with the content over $q=0.100$ pts. wt.), namely, $q=0.250 \div 1.000$ pts. wt., leads to a decrease in the elasticity modulus of materials in bending to $E=$ $2.51 \div 3.00 \mathrm{GPa}$. 
To confirm the above results, impact toughness of epoxy composites filled with different content of MMSCO was investigated at the next stage (Fig. 4). It is established experimentally that in case of adding MMSCO in the amount of $q=0.025$ pts. wt., impact toughness increases relative to the original matrix $\left(a=7.27 \mathrm{~kJ} / \mathrm{m}^{2}\right)$ and is $a=$ $15.45 \mathrm{~kJ} / \mathrm{m}^{2}$. The maximum on the curve showing dependence of impact toughness on the MMSCO content $a=18.53 \mathrm{~kJ} / \mathrm{m}^{2}$ was found in case of adding MMSCO in the amount of $q=0.050$ pts. wt., which is consistent with the results of investigations into the elasticity modulus in bending and indicates the intensification of crosslinking processes at the given filling rate of the CM. Further addition of the filler in the amount of $q=0.100$ pts. wt. contributes to a slight decrease in impact toughness ( $a=$ $17.93 \mathrm{~kJ} / \mathrm{m}^{2}$ ). Further increase in the filler content to $q=$ 1.000 pts. wt. leads to a glut of the composite with the additive, and deterioration of its wetting. In turn, this causes intense crack propagation in materials during impact and, consequently, a decrease in impact toughness. In this case, impact toughness is $a=8.00 \div 15.65 \mathrm{~kJ} / \mathrm{m}^{2}$.

Based on the results of the investigations into the physical and mechanical properties of the MMSCOfilled epoxy $\mathrm{CM}$, it was found that the maximum value of fracture stresses in bending of the $\mathrm{CM}$ is $\sigma_{b}=74.45 \mathrm{MPa}$ (for content $q=0,100$ pts. wt.), the elasticity modulus in bending is $E=3.48 \mathrm{GPa}$ (for content $q=1.000$ pts. wt.), and impact toughness is $a=18.53 \mathrm{~kJ} / \mathrm{m}^{2}$ (for content $q=$ 0.050 pts. wt.). The following should be noted. Despite the fact that during the experimental studies the maximum values of fracture stresses in bending of the CM were attained (Fig. 3, curve 1), attention should be paid to the elasticity modulus in bending (Fig. 3, curve 2) and impact toughness (Fig. 4). Their values at the critical MMSCO content are quite different. This indicates thermodynamic instability of materials. In view of the above, to obtain a CM with a set of the necessary physical and mechanical properties, it is advisable to add the MMSCO filler in the amount of $q=0.050 \div 0.250$ pts. wt. to the epoxy binders.

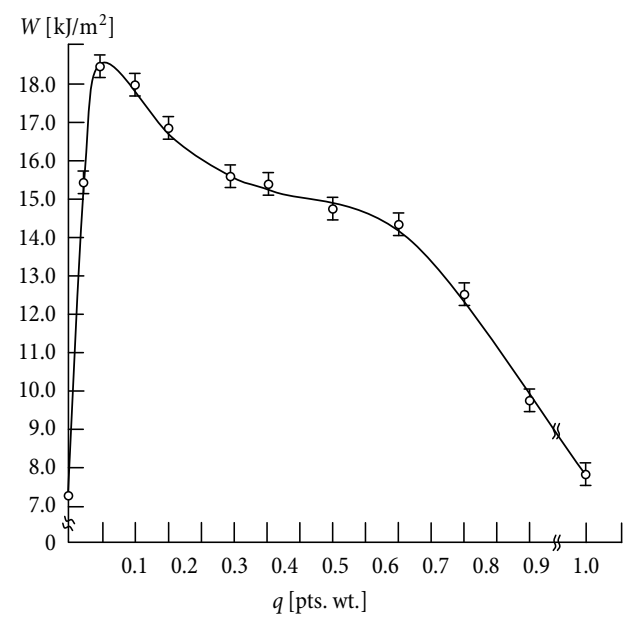

Fig. 4. Dependence of impact toughness of CM on MMSCO content
At the final stage, fracture surfaces of the epoxy matrix and MMSCO-filled composites were investigated by the method of optical microscopy (Fig. 5). The analysis of photos at magnification $\times 200$ and $\times 400$ reveals the presence of shallow lines of chipping in the epoxy matrix, which form the surface relief, with the ductile character of fracture and a significant stress state (Fig. $5 \mathrm{a}, \mathrm{b}$ ).

The analysis of photos of the MMSCO-filled composites in the amount of $q=0.025$ pts. wt. allowed revealing microcracks across the fracture surface (Fig. $5 \mathrm{c}$, d). A homogeneous nature and a small size of microcracks allows stating that the material was formed with an insignificant stress state (relative to the epoxy matrix) and residual stress.

While increasing the filler content in the binder to $q=0.050 \div 0.100$ pts. wt., a fracture structure was observed, which is characterized by large 'main' cracks, which for the most part, do not become microcracks (Fig. 5e-h). This suggests slowing down of the crack propagation process upon interaction of the filler particles or their agglomerates with the epoxy binder. However, under the influence of critical loads, ductile fracture was observed, which is typical of the CM with a high cohesive strength. It should be noted that under the given content of MMSCO, the maximum values of the elasticity modulus in bending (Fig. 3, curve 2) and impact toughness (Fig. 4) were observed. This further confirms the above assumptions.

The study of fracture patterns of the CM filled with MMSCO in the amount of $q=0.250 \div 1.000$ pts. wt. revealed a fracture pattern slightly different from that described above, in which needle formations dominate (Fig. 5i-m). We can assume that an increase in the filler content prevents the development of local shears and cracks due to the placing of macromolecules in the near surface layers in the process of the CM formation.

The analysis of fractograms of fracture surfaces of materials obtained by optical microscopy revealed the correlation between research results on the physical and mechanical properties of the CM, which confirms the reliability of the results obtained. For a more detailed study of the crosslinking processes of epoxy composites and confirmation of the results of physical and mechanical properties of the developed materials, the infrared spectral analysis was conducted. We considered it appropriate to conduct the infrared spectral analysis of a CM with the MSKOS particles content of $q=0.050$ pts. wt., since an improvement of properties was observed with this content (Fig. 6).

Based on the IR-spectra analysis (Fig. 6, spectrums 1 and 2), we established a reduction in the studied parameters (transmission intensity - by $\Delta T=1.5 \%$, half-width by $\Delta b=36.1 \mathrm{~cm}^{-1}$, relative value of the peak area - by $\Delta S=35.5 \%)$ at the wave number $v=582.50 \mathrm{~cm}^{-1}$. This indicates an increase in the density of the spatial grid of the polymer as a result of introducing the MSKOS particles, which limits the mobility of segments of the epoxy binder. Under these conditions, the rigidity of the system increases and, consequently, the indicators of the physical and mechanical properties improve. 
a)

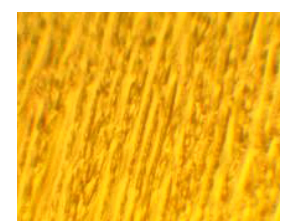

f)

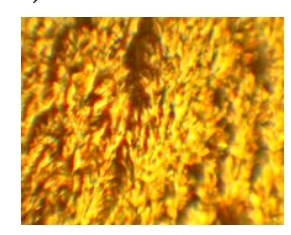

k)

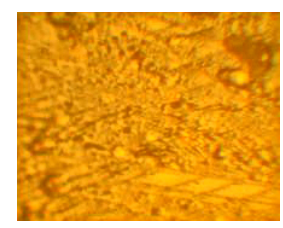

b)

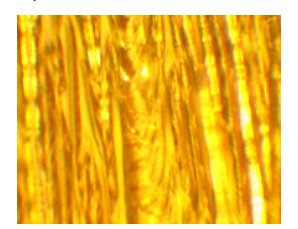

g)

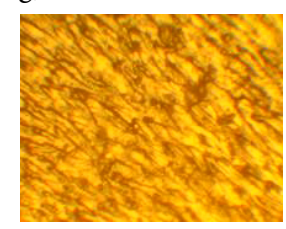

1)

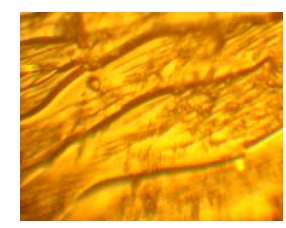

c)

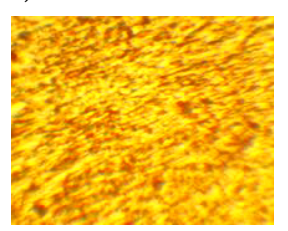

h)

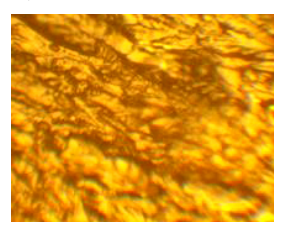

m)

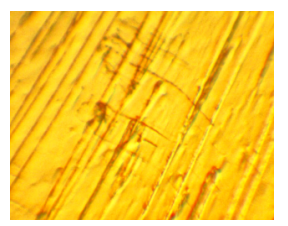

d)

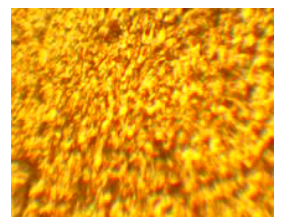

i)

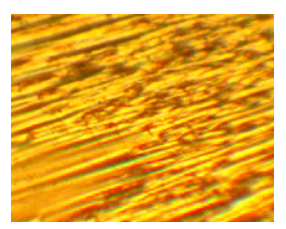

n)

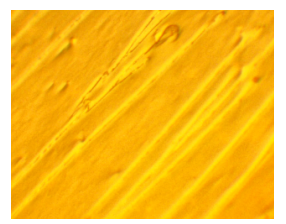

e)

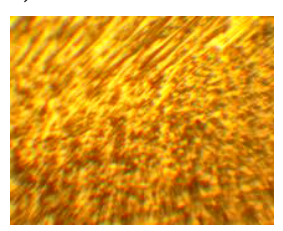

j)

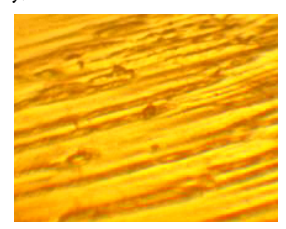

Fig. 5. Fractograms of fracture surfaces of the original matrix and MMSCO-filled epoxy CMs: a, b - epoxy matrix (control specimen); $\mathrm{c}, \mathrm{d}-\mathrm{q}=0.025$ pts. wt. of the filler; $\mathrm{e}, \mathrm{f}-q=0.050$ pts. wt. of the filler; $\mathrm{g}, \mathrm{h}-q=0.100$ pts. wt. of the filler; $\mathrm{i}, \mathrm{j}-q=0.250$ pts. wt. of the filler; $\mathrm{k}, \mathrm{l}-q=0.500$ pts. wt. of the filler; $\mathrm{m}, \mathrm{n}-q=1.000$ pts. wt. of the filler; $(\times 400-a, b, d, f, h, j, l, m, n)$ and $(\times 200-c, e, g, i)$

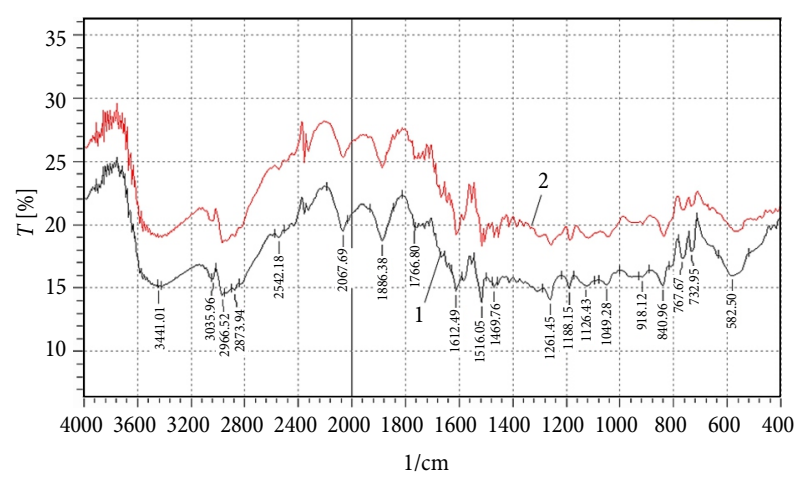

Fig. 6. IR spectra of the epoxy matrix (spectrum 1) and the composite with the MSKOS (spectrum 2) content of $q=0.050$ pts. wt. in the range of wave numbers $v=4000 \div 400 \mathrm{~cm}^{-1}$

It should be noted that a decrease in parameters $T, b$, $S$ was observed at wave numbers $v=732.95 \mathrm{~cm}^{-1}, v=$ $767.67 \mathrm{~cm}^{-1}, v=918.12 \mathrm{~cm}^{-1}, v=1261.45 \mathrm{~cm}^{-1}, v=$ $1886.38 \mathrm{~cm}^{-1}, v=2067.69 \mathrm{~cm}^{-1}$. This indicates the interfacial physical and chemical interaction between active centers on the surface of the particles and functional groups of the epoxy binder, resulting in the limited mobility of -NH-, $-\mathrm{CH}$ - groups (at $\mathrm{v}=732.95 \mathrm{~cm}^{-1}, \mathrm{v}=$ $767.67 \mathrm{~cm}^{-1}$ ), $-\mathrm{C}-\mathrm{C}-\mathrm{C}-\mathrm{N}-$ bonds, $-\mathrm{C}-\mathrm{O}-$ and epoxy groups (at $\mathrm{v}=918.12 \mathrm{~cm}^{-1}$ ), $-\mathrm{O}-\mathrm{H},-\mathrm{C}-\mathrm{N}-$ bonds, $-\mathrm{C}-\mathrm{O}-$, epoxy, aminogroups $-\mathrm{NH} 2$, and $\mathrm{NH}-\mathrm{R}$ (at $\mathrm{v}=$ $1261.45 \mathrm{~cm}^{-1}$ ). Additionally, a reduction in parameters $T$ (by $0.4 \%$ ), $b\left(19.2 \mathrm{~cm}^{-1}\right), S$ (by $22.0 \%$ ) at the wave number $v=2067.67 \mathrm{~cm}^{-1}$ was observed, indicating the crosslinking of triple groups $\mathrm{C} \equiv \mathrm{C}, \mathrm{C} \equiv \mathrm{N}$. Of particular note is the reduction in parameters $T, b, S$ in the range of wave numbers $v=2873.94 \div 3035.96 \mathrm{~cm}^{-1}$. The analysis of papers (Stuhlyak, Buketov 2009; Buketov et al. 2015a, 2015b; Kortaberria et al. 2011) allows stating that $-\mathrm{C}-\mathrm{H}$ groups, groups of methyl radical $\left(\mathrm{CH}_{3}-\mathrm{C}\right)$ and hydroxyl groups participate in the reactions with the active centers on the surface of the MSKOS particles. At the same time, a reduction in the relative value of the peak area (by $\Delta S=$ $29.2 \%$ ) at $v=3441.01 \mathrm{~cm}^{-1}$ indicates that groups $\mathrm{OH}$ and -NN- are involved in the reactions of interfacial interactions. Under these conditions, the physical and mechanical properties of the filled polymer are enhanced.

\section{Practical Using}

The results obtained allow using CMs or protective coatings based on them to restore the process equipment and corrosion protection of deck machinery (Gudze, Melchers 2008; Slater 1994). The developed materials are planned to be used on the dry cargo ship Oles Honchar with the deadweight of 6315 tons (Fig. 7) to improve the corrosion properties of deck machinery (Fig. 8), as well as to restore and improve performance characteristics of stern tube systems (Fig. 9).

An increased resistance to corrosion is planned to be achieved by using a two-layer epoxy composite coating. The protective epoxy composite coating is applied to the elements of deck machinery by the method of pneumatic spraying of the adhesive layer with a thickness of $0.1 \div 0.3 \mathrm{~mm}$ (MMSCO content $q=0.150$ pts. wt.), which allows to significantly increase the adhesive strength and corrosion resistance of protective coatings. Under operating conditions of the ship, it is not always possible to 


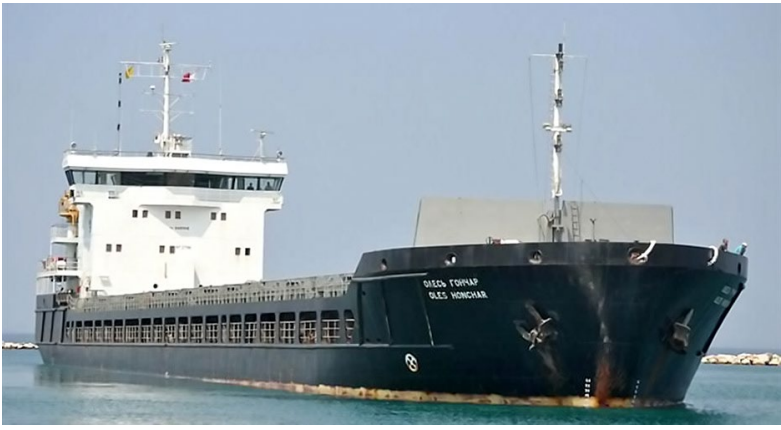

Fig. 7. Dry cargo ship Oles Honchar with the deadweight of 6315 tons (MarineTraffic 2015)

use thermo cabinets to withstand the temperature and time regimes. In this case, it is necessary to perform a preliminary polymerization of the adhesive layer at a temperature $T=293 \div 323 \mathrm{~K}$ over time $\tau=30 \div 120 \mathrm{~min}$, which provides for a high degree of crosslinking of macromolecules to form a spatial grid. This, in turn, leads not only to improvements in the adhesive strength, but also in the physical and mechanical properties of the coating. The application of the adhesive layer with the thickness, which is $0.1 \mathrm{~mm}$ less, worsens the course of diffusion processes during polymerization of the protective coating. The application of the adhesive layer with the thickness, which is $0.3 \mathrm{~mm}$ greater, reduces the value of the adhesive strength in heterogeneous materials (Stukhlyak et al. 2015).

The functional layer (with the MMSCO content $q=$ $0.050 \div 0.250$ pts. wt.) with a thickness of $1.5 \div 2.0 \mathrm{~mm}$ should be applied to the adhesive layer after a preliminary polymerization. The available experimental results of comparative tests of physical and mechanical, thermal properties and corrosion resistance of the developed and known protective coatings indicate high performance and appropriateness of using new materials in shipbuilding (Mouritz et al. 2001). Restoration of the stern tube bearing (Fig. 9b) and increasing performance (through replacement) of the intermediate shaft bearings is planned to be achieved by using compositions with the MMSCO content $q=0.050$ pts. wt., since with such content an enhancement of the adhesion, physical and mechanical properties of the CM was observed. Recovery was performed after pre-cleaning and degreasing of surfaces, and then the recovery layer was applied using the above technology (pulverization spraying).

To replace the thrust bearing (Fig. 9c), the damaged material (babbit) was dismantled, then the $\mathrm{CM}$ was formed using the above technology in the temperature and time regimes of polymerization and ultrasonic treatment. Then the preformed epoxy composition was poured into a cold or hot form by means of free casting with subsequent polymerization without pressure. Moreover, the preset mode of hardening was maintained. Upon completion of the above operations, the bearing was installed with the observation of the preset dimensions and tolerances. a)

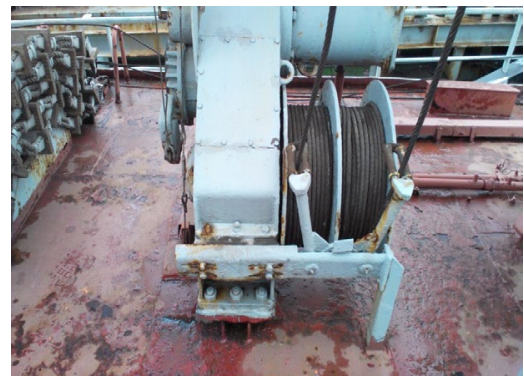

b)

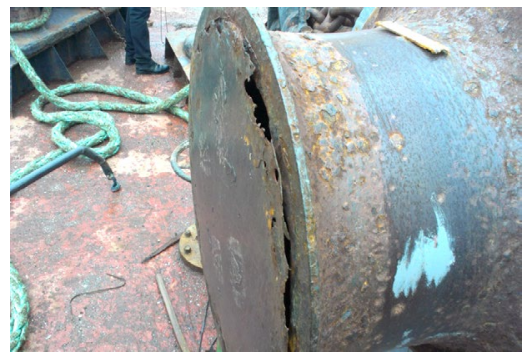

c)

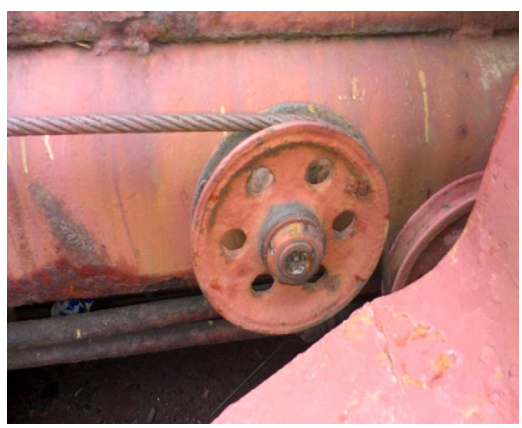

d)

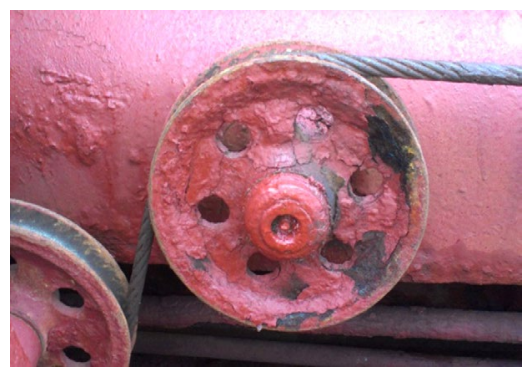

e)

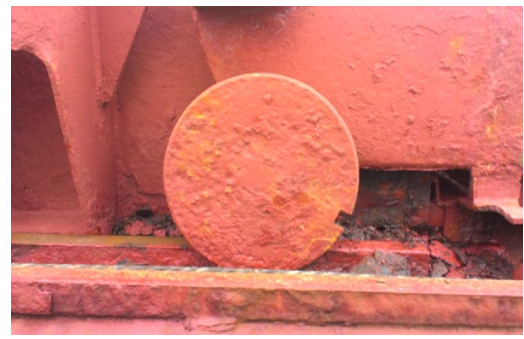

f)

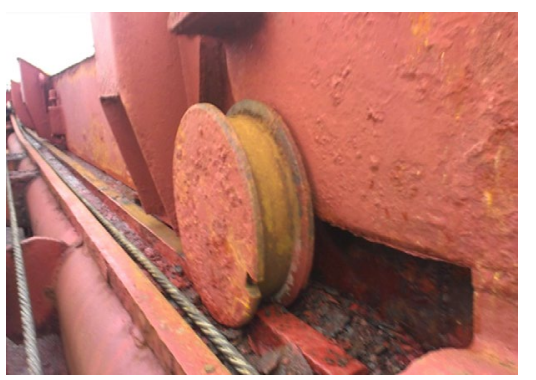

Fig. 8. Some types of damage of deck machinery due to corrosion fracture on dry cargo ship Oles Honchar 
a)

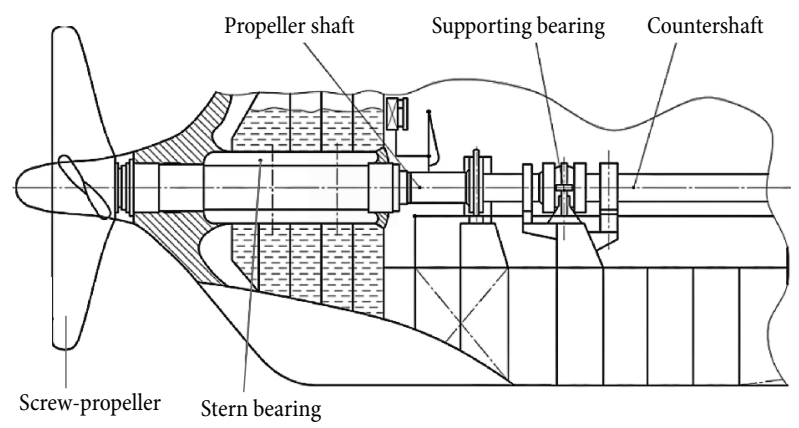

b)

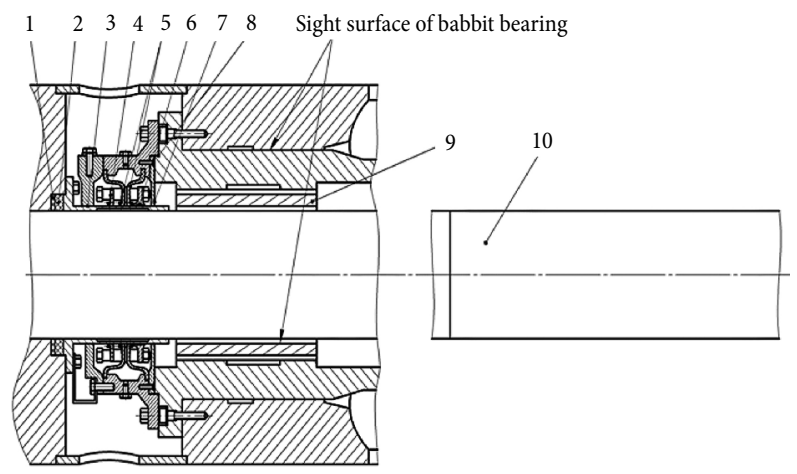

c)

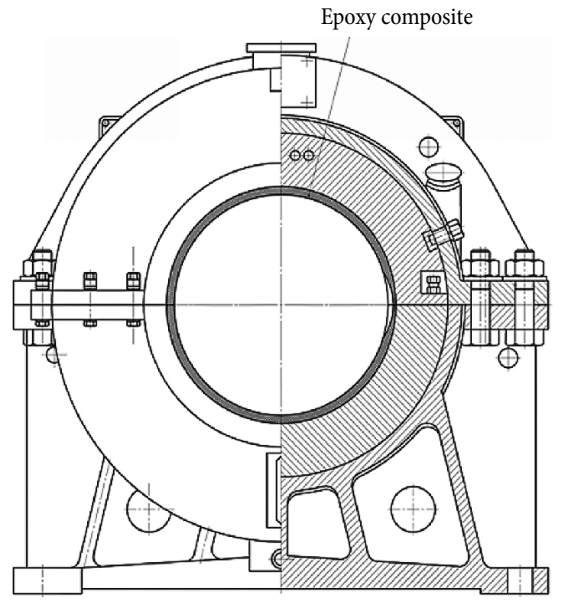

Fig. 9. Renewal and replacement of structural elements with epoxy composites: a - general scheme of shafting; b - stern bearing; $\mathrm{c}$ - thrust bearing of intermediate shaft; 1 - adjusting ring at the point of the screw; 2 - rubber rings; 3 - aft cover; 4 - sealing cuffs; 5 - bellows-sealed cuff; 6 - spiral spring; 7 forward cover; 8 - pad; 9 - babbit bearing; 10 - stern shaft

\section{Conclusions}

The optimum MMSCO content in the epoxy matrix with improved adhesive properties is determined. The maximal adhesive strength of the CM in isolation $\left(\sigma_{a}=40.05 \mathrm{MPa}\right)$ was observed at the filler content $q=$ 0.050 pts. wt. However, the maximal adhesive strength in shear $(\tau=12.83 \mathrm{MPa})$ was observed in the CM with the MMSCO content of $q=0.250$ pts. wt. To form the coatings of different functions, namely with the maximum values of $\sigma_{a}$ and $\tau$, it is advisable to use the CM with the MMSCO content $q=0.150$ pts. wt. A material of this kind has the following properties: adhesion strength in isolation $\sigma_{a}=36.60 \mathrm{MPa}$, in shear $\tau=11.80 \mathrm{MPa}$, residual stresses $\sigma_{\text {res }}=0.96 \mathrm{MPa}$.

It is proved that for the formation of composites with the improved physical and mechanical properties it is necessary to add MMSCO in the amount of $q=0.050 \div 0.250$ pts. wt. into the epoxy diane oligomer ED-20 (100 pts. wt.). In this case the material is formed with the following properties: fracture stress in bending $\sigma_{b}=48.00 \div 50.00 \mathrm{MPa}$, elasticity modulus in bending $E=3.00 \div 3.24 \mathrm{GPa}$.

Additionally it was found that the obtained values of impact toughness of composites during the introduction of MMSCO into the binder increased by 2.5 times compared to the epoxy matrix. Moreover, the maximum capacity to resist impact loads, including fracture toughness, was demonstrated by the CM with the filler content $q=0.050$ pts. wt. Impact toughness of this CM is $a=$ $18.53 \mathrm{~kJ} / \mathrm{m}^{2}$.

The method of optical microscopy was used to investigate fracture surface of the epoxy matrix and the developed CMs. The analysis of fractograms of the fracture surface of the epoxy matrix allowed us to determine the surface topography with a ductile nature of fracture, and a significant stress state. Fractograms of fracture surfaces of the filled composites are characterized both by the presence of homogeneous microcracks and the formation of elongated needle-like structures, which indirectly suggests the improved cohesive properties of materials.

Epoxy CMs and coatings based on them are developed with a view to improving the corrosion properties of the deck machinery of the sea and river dry cargo vessels, as well as restoring and improving the performance characteristics of structural elements of stern tube systems.

\section{References}

Atta, A. M.; Abdou, M. I.; Elsayed, A.-A. A.; Ragab, M. E. 2008. New bisphenol novolac epoxy resins for marine primer steel coating applications, Progress in Organic Coatings 63(4): 372-376. http://doi.org/10.1016/j.porgcoat.2008.06.013

Atta, A. M.; El-Mahdy, G. A.; Al-Lohedan, H. A.; Ezzat, A. O. 2014. Synthesis and application of hybrid polymer composites based on silver nanoparticles as corrosion protection for line pipe steel, Molecules 19(5): 6246-6262. http://doi.org/10.3390/molecules19056246

Buketov, A. V.; Krasnen'kyi, V. M. 2013. Influence of the range of particle sizes of the filler on the adhesion strength and residual stresses in epoxy composites, Materials Science 48(4): 521-530. http://doi.org/10.1007/s11003-013-9533-2

Buketov, A.; Maruschak, P.; Sapronov, O.; Brailo, M.; Leshchenko, O.; Bencheikh, L.; Menou, A. 2016. Investigation of thermophysical properties of epoxy nanocomposites, Molecular Crystals and Liquid Crystals 628(1): 167-179. http://doi.org/10.1080/15421406.2015.1137122

Buketov, A. V.; Sapronov, O. O.; Aleksenko, V. L. 2015a. Epoksydni nanokompozyty: monografiya. Kherson: KhDMA. 184 s. (in Ukrainian). 
Buketov, A. V.; Zinchenko, D.A.; Sapronov, A. A.; Yacyuk, V. N. 2015b. Vliyanie mikrodispersnogo karbonata serebra na svojstva jepoksikompozitov, Mehanika kompozicionnyh materialov i konstrukcij 21(4): 534-548. (in Russian).

Caines, S.; Khan, F.; Shirokoff, J.; Qiu, W. 2015. Experimental design to study corrosion under insulation in harsh marine environments, Journal of Loss Prevention in the Process Industries 33: 39-51. http://doi.org/10.1016/j.jlp.2014.10.014

Decò, A.; Frangopol, D. M.; Zhu, B. 2012. Reliability and redundancy assessment of ships under different operational conditions, Engineering Structures 42: 457-471.

http://doi.org/10.1016/j.engstruct.2012.04.017

Dobrotvor, I. H.; Stukhlyak, P. D.; Buketov, A. V. 2009. Determination of the ranges of the optimal content of a dispersed filler in epoxy composites, Materials Science 45(6): 790-797. http://doi.org/10.1007/s11003-010-9244-x

Dong, S. G.; Zhao, B.; Lin, C. J.; Du, R. G.; Hu, R. G.; Zhang, G. X. 2012. Corrosion behavior of epoxy/zinc duplex coated rebar embedded in concrete in ocean environment, Construction and Building Materials 28(1): 72-78. http://doi.org/10.1016/j.conbuildmat.2011.08.026

Heller, S. R. 1970. The use of composite materials in naval ships, in F. W. Wendt, H. Liebowitz, N. Perrone (Eds.). Mechanics of Composite Materials: Proceedings of the Fifth Symposium on Naval and Structural Mechanics, 69-111.

GOST 10587-84. Smoly jepoksidno-dianovye neotverzhdennye. Tehnicheskie usloviya [Uncured Epoxy Resins. Specifications] (in Russian).

GOST 9550-81. Plastmassy. Metody opredelenija modulja uprugosti pri rastjazhenii, szhatii i izgibe [Plastics. Methods for Determination of Elasticity Modulus at Strength, Compression and Bending] (in Russian).

GOST 4647-80. Plastmassy. Metod opredelenija udarnoj vjazkosti po Sharpi [Plastics. Method for Determination of Charpy's Impact Strength] (in Russian).

GOST 4648-71. Plastmassy. Metod ispytaniya na staticheskij izgib [Plastics. Method of Static Bending Test] (in Russian).

GOST 14760-69. Klei. Metod opredeleniya prochnosti pri otryve [Adhesives. Method of Determination of Tensile Strength] (in Russian).

GOST 14759-69. Klei. Metod opredelenija prochnosti pri sdvige [Adhesives. Method of Determination of Shear Strength] (in Russian).

Gudze, M. T.; Melchers, R. E. 2008. Operational based corrosion analysis in naval ships, Corrosion Science 50(12): 3296-3307. http://doi.org/10.1016/j.corsci.2008.08.048

James, M. N.; Hattingh, D. G. 2015. Case studies in marine concentrated corrosion, Engineering Failure Analysis 47(A): 1-15. http://doi.org/10.1016/j.engfailanal.2014.08.013

Kortaberria, G.; Arruti, P.; Mondragon, I.; Vescovo, L.; Sangermano, M. 2011. Dynamics of in situ synthetized silverepoxy nanocomposites as studied by dielectric relaxation spectroscopy, Journal of Applied Polymer Science 120(4): 2361-2367. http://doi.org/10.1002/app.33440

MarineTraffic. 2015. Maritime Database. Photos of Dry Cargo Ship 'Oles Honchar'. Available from Internet: http://www. marinetraffic.com/en/photos/of/ships/shipid:344257

Melchers, R. E. 2012. Modeling and prediction of long-term corrosion of steel in marine environments, International Journal of Offshore and Polar Engineering 22(4): 257-263.

Melchers, R.; Jeffrey, R. 2008. The critical involvement of anaerobic bacterial activity in modelling the corrosion behaviour of mild steel in marine environments, Electrochimica Acta 54(1): 80-85. http://doi.org/10.1016/j.electacta.2008.02.107
Montemor, M. F. 2014. Functional and smart coatings for corrosion protection: a review of recent advances, Surface and Coatings Technology 258: 17-37.

http://doi.org/10.1016/j.surfcoat.2014.06.031

Mouritz, A. P; Gellert, E; Burchill, P.; Challis, K. 2001. Review of advanced composite structures for naval ships and submarines, Composite Structures 53(1): 21-42. http://doi.org/10.1016/S0263-8223(00)00175-6

Nakai, T.; Matsushita, H.; Yamamoto, N. 2007. Pitting corrosion on epoxy-coated surface of ship structures, in International Symposium on Shipbuilding Technology (ISST 2007) - Fabrication and Coatings, 6-7 September 2007, Osaka, Japan, 59-63.

Pascault, J.-P.; Williams, R. J. J. 2010. Epoxy Polymers: New Materials and Innovations. Wiley-VCH. $387 \mathrm{p}$. http://doi.org/10.1002/9783527628704

Slater, J. E. 1994. Selection of a blast-resistant GRP composite panel design for naval ship structures, Marine Structures 7(2-5): 417-440. http://doi.org/10.1016/0951-8339(94)90033-7

Stuhlyak, P. D.; Buketov, A. V. 2009. Epoksykompozytni materialy, modyfikovani ul'trafioletovym oprominennyam. Ternopil': Zbruch. 237 s. (in Ukrainian).

Stukhlyak, P. D.; Buketov, A. V.; Panin, S. V.; Maruschak, P. O.; Moroz, K. M.; Poltaranin, M. A.; Vukherer, T.; Kornienko, L. A.; Lyukshin, B. A. 2015. Structural fracture scales in shock-loaded epoxy composites, Physical Mesomechanics 18(1): 58-74. http://doi.org/10.1134/S1029959915010075

TU 6-05-241-202-78. Polijetilenpoliaminy (PEPA): Tehnicheskie uslovija (in Russian).

Yu, Y.-H.; Ma, C.-C. M.; Teng, C.-C.; Huang, Y.-L.; Tien, H.-W.; Lee, S.-H.; Wang, I. 2013. Enhanced thermal and mechanical properties of epoxy composites filled with silver nanowires and nanoparticles, Journal of the Taiwan Institute of Chemical Engineerss 44(4): 654-659. http://doi.org/10.1016/j.jtice.2013.01.001

Zayed, A.; Garbatov, Y.; Guedes Soares, C. 2013. Reliability of ship hulls subjected to corrosion and maintenance, Structural Safety 43: 1-11. http://doi.org/10.1016/j.strusafe.2013.01.001 